\title{
Comparison of Canonical Correlation and Interbattery Factor Analysis on Sensation Seeking and Drug Use Domains
}

\author{
G. J. Huba, M. D. Newcomb, and P. M. Bentler \\ University of California, Los Angeles
}

The relationships between different types of sensation-seeking tendencies and the use of 26 substances are studied for a group of 1,068 adolescents. The methods of canonical correlation analysis with dimension rotation and maximum likelihood interbattery factor analysis are contrasted in the data set. Several major patterns are found, and it is concluded that the relationship between drug use and sensation-seeking tendencies is not a general one.

In recent years there has been a resurgence of interest in different ways to explore predictorcriterion relationships using factor analysis of only those dimensions that are common to pairs of domains or by improved interpretability of canonical correlation solutions (Bentler \& Huba, in press; Browne, 1979; Cliff \& Krus, 1976; Skinner, 1977, 1978; Tucker, 1958). Two mathematically similar but philosophically different models underlie the bulk of the methodological suggestions. The manifest variable alternative, canonical correlation analysis, is a method for determining linear combinations of the original variables under the constraint that composites formed in the two domains be mutually orthogonal within domains and maximally correlated with corresponding combinations in the other domains. Skinner $(1977,1978)$ has sug-

APPLIED PSYCHOLOGICAL MEASUREMENT Vol. 5, No. 3, Summer 1981, pp. 291-306

(C) Copyright 1981 Applied Psychological Measurement Inc. 0146-6216/81/030291-16\$1.80 gested several ways of altering the components so as to rotate dimensions for maximal correspondence to original variables, whereas Cliff and Krus (1976), as well as Bentler and Huba (in press), considered ways to rotate the derived canonical dimensions to positions where the pattern of loadings (or weights) meets some "simple structure" or simplicity criterion. Thus, the first approach to the problem of structuring the covariation in common between domains involves the use of canonical correlation analysis with either a correspondence or simplicity rotation to improve interpretability. Advantages of the canonical correlation approach are the relative inexpensiveness of the procedure, the wide circulation of efficient computer programs, the determinacy of scores, the transformation-freeness of the solution, and the large-sample test for the number of significant dimensions (Mardia, Kent, \& Bibby, 1979).

Several decades ago, Tucker (1958) proposed the interbattery factor analysis model as a means of determining those factors in common to two domains of variables. At the time, Tucker's least squares solution to the problem of communality estimation for factor analysis was ingenious; an explicit solution was available when there was focus on the factors influencing both domains. Recently, Browne (1979) showed that maximum likelihood estimates of the factor loadings in the interbattery factor analysis model can be obtained by a column rescaling of 
the canonical correlation loadings matrices. Browne's comprehensive study of the interbattery method showed that many advantages of canonical correlation analysis could be transferred to the interbattery factor analysis model. First, since maximum likelihood interbattery factor analysis loadings are a column rescaling of the canonical correlation loadings, the wide availability of computer programs for canonical correlation analysis (and loadings matrices) makes interbattery factor analysis generally available. Second, the relationship to the scale-free canonical solution by a column rescaling also establishes the scale-freeness of the interbattery solution. Third, as Browne has noted, the fact that maximum likelihood estimates have been obtained makes it possible to apply the result of Rao (1973) - that the standard tests for the number of significant canonical correlations (and dimensions) are also tests for the number of interbattery factors. Tucker (1958) and Browne (1979) have commented, however, on the relatively high indeterminacy of the interbattery factor analysis model, and Browne's estimates were derived under the usually tenable assumption that domains of variables are equally predictive of the underlying interbattery factors.

The major difference between canonical correlation and interbattery factor analysis lies in the focus upon correlations among sets of derived linear combinations versus loadings of the original variables on inferred, "error-free," latent constructs or factors. The canonical correlation model assesses the way in which weighted sums of the original variables interrelate. The correlations across domains will not, in general, be perfect. The interbattery factor model, in contrast, assumes that the same factors (i.e., cross-set perfectly correlated factors) influence the variables in the two domains. The interbattery model determines how many such factors there are, as well as the pattern of correlation between variables in the two domains implied by the interbattery factors.

This paper compares the methods in two domains that have recently generated theoretical interest. Repeated research efforts have consistently shown that drug-taking behaviors are significantly related to sensation-seeking behaviors (Khavari, Mabry, \& Humes, 1977; Segal, Huba, \& Singer, 1980; Zuckerman, 1978, 1979; Zuckerman, Buchsbaum, \& Murphy, 1980). Interestingly, the current theoretical debate about the function of drug use in satisfying sensationseeking needs (Segal et al., 1980), as opposed to an interpretation that sensation-seeking tendencies and drug-taking proclivities are generally "caused" by the same biological processes (Zuckerman et al., 1980), tends to parallel the different philosophies underlying the canonical correlation and interbattery factor analysis approaches. Zuckerman et al. (1980) favors the "common cause" interpretation, whereas Segal et al. (1980) take a more dynamic approach to explaining the relationships. The dynamic theoretical approach is more fully explicated in the DOMAIN model of Huba and Bentler (in press).

\section{Method}

\section{Participants}

The participants in this study were a group of 1,068 individuals in an ongoing longitudinal study of adolescent growth (see Huba, Wingard, $\&$ Bentler, 1979, 1980). The numbers of adolescents of each gender by grade were: 153 tenthgrade boys, 130 eleventh-grade boys, 81 twelfthgrade boys, 275 tenth-grade girls, 248 eleventhgrade girls, and 181 twelfth-grade girls.

\section{Drug Use Indicators}

The 26 drug use measures were frequencies of use in the past 6 months. The responses for the different drugs were rated on a 7 -point anchored scale $(1=$ never, $2=$ once, $3=$ a few times, $4=$ once a month, $5=$ once a week, $6=$ once $a$ day, $7=$ more than once a day). The full list of drug use categories is presented in Table 1. 


\section{Sensation-Seeking Items}

Participants also completed a brief questionnaire about their sensation-seeking tendencies. Individuals were asked, "How of ten do you feel the following way?" Abbreviated versions of the 16 items are presented in Table 3. Participants responded to the items on an anchored 5-point scale $(1=$ never, $2=$ rarely, $3=$ sometimes, $4=$ usually, $5=$ always).

The 16 items were chosen as follows. Zuckerman, Eysenck, and Eysenck (1978) present the derivation of the Sensation-Seeking Scales, Form V, which are 10-item, forced-choice indices for Experience Seeking, Thrill and Adventure Seeking, Disinhibition, and Boredom Susceptibility. In order to provide brief indices, four positive choice statements from each construct were selected based on a high loading in American and British samples and on judged relevance for adolescents. In the current questionnaire, Items 1, 5, 9, and 13 were designed to be measures of Experience Seeking, Items 2, 6, 10, and 14 were measures of Thrill and Adventure Seeking, Items $3,7,11$, and 15 were hypothesized to be items assessing Disinhibition, and Items $4,8,12$, and 16 were presumed to be measures of Boredom Susceptibility. The value of coefficient alpha for Experience Seeking was .43, for Thrill and Adventure Seeking it was .70, for Disinhibition it was .68, and for Boredom Susceptibility it was .43. Since the internal consistency coefficients for the scales were only marginally acceptable, analyses using both original items and derived scales are reported.

\section{Data Analysis}

For the first two analyses, the four sensationseeking scale scores and the 26 drug use items were used in a canonical correlation analysis with the sensation-seeking scales forming one set and the drug use items forming the remaining set. The loadings (correlations of variables with canonical variates) were input into an orthogonal asymmetric rotation procedure called two-matrix orthosim in the program developed by Huba, Palisoc, and Bentler (in press). The rotated canonical correlation loadings constitute the first analysis. For the second analysis, the unrotated canonical correlation loadings were rescaled using Browne's (1979) results so that maximum likelihood interbattery factor loadings were obtained. The interbattery factor loadings were also orthogonally rotated using the orthosim method in Huba, Palisoc, and Bentler's (in press) program. For the third and fourth analyses, the 16 original sensation-seeking items and the 26 drug use items were used in a canonical correlation analysis with the loadings again rotated. An interbattery factor analysis solution for these data was also derived and orthogonally rotated.

\section{Canonical Correlation Rotation}

In asymmetric orthogonal canonical correlation rotation, the two matrices of loadings yielded by canonical correlation analysis are transformed using a different orthonormal matrix for each set of loadings. That is, let $\mathbf{A}$ be a $p \times r$ matrix of the loadings of $p$ Set 1 variables on $r$ canonical variates. Let $\mathbf{B}$ be a $q \times r$ matrix of loadings of the $q$ Set 2 variables on the $r$ canonical variates. These two matrices of loadings are the correlations of the original variables with the canonical variates or, alternately, the standardized regression coefficients of the original variates on the canonical variates. Let $\mathbf{U}$ be the $r \times r$ diagonal matrix of the canonical correlations, i.e., the correlations between the derived variates for Set 1 and the derived variates for Set 2 . As shown by Bentler and Huba (in press), the problem in asymmetric orthogonal canonical correlation rotation is to find the $r \times r$ orthonormal matrices $T_{1}$ and $\mathbf{T}_{2}$ so that the matrices $\mathbf{C}$ and $\mathbf{D}$, as defined in Equations 1 and 2, satisfy some overall simplicity criterion that is a joint function of the two matrices. Bentler and Huba (in press) apply Bentler's (1977) orthosim criterion and call the procedure that finds the matrices $\mathbf{T}_{1}$ and $\mathbf{T}_{2}$ the asymmetric two-matrix orthosim method. 


$$
\begin{aligned}
& \mathrm{C}=\mathrm{AT}_{1} \\
& \mathrm{D}=\mathrm{BT}_{2}
\end{aligned}
$$

As a point of clarification, it should be noted that in this paper the canonical correlation loadings, rather than the weights, were rotated. Corresponding to the loadings matrices $\mathbf{A}$ and $\mathbf{B}$ for the two sets of variables are the matrices $\mathbf{G}$ and $\mathbf{H}$, which are $p \times r$ and $q \times r$ matrices, respectively, of the weights to be applied to the variables in each set to obtain the standardized canonical variates. The loadings matrices $\mathbf{A}$ and $\mathbf{B}$ are related to the weights matrices and the matrices $\mathbf{R}_{x x}$ and $\mathbf{R}_{y y}$ of the correlations among the variables in the two sets through the relationships depicted in Equations 3 and 4.

$$
\begin{aligned}
& A=R_{x x} G \\
& B=R_{y y} H
\end{aligned}
$$

It is important to realize that simplicity is being sought in the rotated loadings matrices $\mathbf{A} \mathbf{T}_{1}$ and BT $_{2}$ rather than in the rotated weights matrices $\mathbf{G T}_{1}$ and $\mathbf{H T}_{2}$. Reasons for maximizing the simplicity criterion as a function of the loadings rather than of the weights have been considered in detail by Bentler and Huba (in press). Conceptually, it should be remembered that the canonical loadings matrices $\mathbf{A}$ and $\mathbf{B}$ are analogous to factor loadings matrices, whereas the weights matrices $\mathbf{G}$ and $\mathbf{H}$ are analogous to factor score coefficient matrices. (See Timm, 1975, for a discussion of weights and loadings matrices.)

After rotating the matrices of canonical variates by the transformation matrices, it is necessary to determine the correlations among the rotated variates in the two sets. It can be easily verified that the canonical correlations after rotation are defined by Equation 5 .

$$
\mathrm{V}=\mathrm{T}_{1}^{\prime} \mathrm{UT} \mathrm{T}_{2}
$$

An orthogonal rotation that guarantees that $\mathbf{V}$ is symmetric can be developed by constraining $\mathbf{T}_{1}$ to be equal to $\mathbf{T}_{2}$. Such solutions were considered by Cliff and Krus (1976) and are called symmetric rotations by Bentler and Huba (in press). Different weighting systems for determining the common $\mathbf{T}$ matrix under this constraint have been considered by Bentler and $\mathrm{Hu}$ ba. This paper used the more general case that does not constrain the two transformation matrices to be equal.

Some examples of canonical correlation rotation that additionally utilize "split samples" to assess robustness are given by Huba, Wingard, and Bentler (1979, 1980), Segal et al. (1980, chap. 8), and Wingard, Huba, and Bentler (1980). The rotations can be made simply and inexpensively (about 1 second for those reported here) and in the Fortran program of Huba, Palisoc, and Bentler (in press).

\section{Maximum Likelihood Interbattery Factor Analysis}

Browne (1979) showed that canonical correlation loadings and maximum likelihood estimates of the factor loadings in the interbattery factor analysis model developed by Tucker (1958) are related by a rescaling when an identification condition is imposed on the interbattery solution. Let $\mathbf{E}$ be the $(p+q) \times r$ supermatrix of unrotated canonical variate loadings formed by concatenating the two matrices $(\mathbf{A}, \mathbf{B})$ of canonical loadings for the variable sets, i.e., as in Equation 6.

$$
E=\left[\begin{array}{l}
A \\
B
\end{array}\right]
$$

Browne (1979, p. 82) then showed that the $(p+q) \times r$ matrix $\mathbf{F}$ of maximum likelihood loadings of the total set of variables on $r$ interbattery factors is derivable from $\mathbf{E}$ and the canonical correlations $\mathbf{U}$ by the relationship shown in Equation 7.

$$
\mathrm{F}=\mathrm{EU}^{.5}
$$

That is, the columns of $\mathbf{E}$, the canonical variate loadings, are rescaled by the square root of the canonical correlations to yield interbattery factor loadings. 
In rotating the loadings, Browne (1979) restricted his attention to the case of a common transformation (T) matrix for $\mathbf{F}_{1}=\mathbf{A} \mathbf{U}^{\cdot 5}$, and $\mathbf{F}_{2}=\mathbf{B U}^{\cdot 5}$. By introducing the column rescaling first and only then rotating by a common transformation matrix, Browne noted that "we have restricted our attention to those sets of inter-battery factors which are equally related to the two sets of observed variables." (1979, p. 83)

\section{Comparison of Canonical Rotation and Inter- battery Solutions}

As sets of mathematical equations, the canonical correlation and interbattery solutions are related to one another before rotation through the column rescaling. Since the same constant is used to rescale corresponding columns of the canonical loadings matrices $\mathbf{A}$ and $\mathbf{B}$, canonical loadings that are large in absolute value will be relatively large in absolute value in the interbattery solution. Thus, dimensions will generally be "labeled" or "interpreted" in the same manner. One point of difference for the unrotated solutions, which is more apparent than real, is that the smaller interbattery factors will have their loadings most reduced in magnitude from the canonical loading matrices because the rescaling will be by the square root of a small canonical correlation. It should be noted, however, that a large loading and a small canonical correlation are being "traded" for a small loading and a "canonical" correlation of unity. In the rotated solutions, the canonical correlation and interbattery solutions will generally be most similar if the two transformation matrices $\left(\mathbf{T}_{1}, \mathbf{T}_{2}\right) \mathrm{em}$ ployed in the canonical rotation are approximately the same and the canonical correlations have similar values.

In summary, there are two major differences between canonical correlation analysis and interbattery factor analysis. The canonical correlation analysis forms linear composites of observed or manifest variables, since the underlying model does not hypothesize measurement error in the variables. In contrast, interbattery factor analysis is a true score or latent variable method that explicitly defines variables with error. Second, and perhaps most critically, canonical correlation analysis forms composites that are only imperfectly related across sets; the canonical correlations are a measure of the magnitude of association between variates formed in the two domains under study. Thus, composites in one set may be highly correlated with composites in the other set but will only be perfectly correlated when there are one or more variables in the second domain that are exact linear combinations of one or more variables in the first domain. This situation almost never occurs in practice. On the other hand, in interbattery factor analysis, dimensions are generated that are presumed to be common "causal" elements for variables in the two different domains (in the factor analytic sense). The corresponding dimensions in the two domains are thus perfectly correlated, since they are generated under the constraint that the same factors operate in the two sets of measures. Thus, a major part of the choice between canonical correlation analysis and interbattery factor analysis lies in the investigator's intention. If the analyst wishes to determine the common latent variable sources of variance for a set of variables that is grouped into two domains, the interbattery model is probably the more appropriate one. If, on the other hand, the investigator wishes to choose a small number of linear combinations of the original variables in each of the two sets in such a way as to maximize the correlations between the domains, then the canonical correlation model is probably more appropriate.

\section{Results}

In the canonical correlation analysis of the four Sensation-Seeking Scale scores against the 26 drug use items, it was found that there was a significant relationship between the domains: $\chi^{2}(104)=490.86, p<.001$. The size of the canonical correlations $(.52, .27, .23$, and .16 for the four dimensions) seems to indicate that there is one major set of relationships spanning domains with the possibility of several minor across-do- 
main relationships. Application of the Bartlett stepdown method indicates that with two dimensions partialled, residual covariation among the domains remained: $\chi^{2}(48)=84.04, p<.001$; with three dimensions partialled, there was no statistically reliable remaining covariation: $\chi^{2}(23)=28.5, p=.20$. Consequently, the hypothesis that there are three dimensions spanning the domains could not be rejected while hy. pothesis of smaller dimensionalities were rejected.

In the canonical correlation solution, it is possible to determine (1) the multivariate association (or correlation) among the domains and (2) how well the variables in one domain predict the variables in the other domain. To quantify the association, Cramer and Nicewander (1979) suggested six coefficients, of which two, $\gamma_{s}$ and $\gamma_{6}$, seem to have reasonably good properties as indices of squared multivariate association. For these data, the square root of $\gamma_{5}$ was .33 , while the square root of $\gamma_{6}$ was .32. Either coefficient indicates moderate levels of association between domains. Stewart and Love (1968) have suggested a directional coefficient of multivariate predictability, the redundancy index. Assuming three significant dimensions, the value of the redundancy index when predicting drug use from the Sensation-Seeking Scales was .0567, indicating that about $6 \%$ of the variance in the drug use variables is explained by that domain. When predicting sensation seeking from drug use, the value of the redundancy index was .1285 . Either way of quantifying multivariate association or predictability allows the conclusion that the relationships among domains are moderate in magnitude.

Although three dimensions were statistically necessary, it is possible that less than three may be required for meaningful interpretation. Therefore, the one-dimensional solution was examined, as well as solutions with two and three rotated dimensions in each domain. Canonical rotations were accomplished using the asymmetric two-matrix orthosim procedure. The loadings for the alternate solutions are shown in Table 1, which also presents the rotation-adjusted canonical correlations.

The three-dimensional solution seems interpretable. It is interesting to note that the first dimension in each of the three different solutions is also about the same: This observation would argue that the orthogonal rotation utilized does not destroy a large general relationship between certain aspects of drug use and the SensationSeeking Scales. The authors' interpretation of the three-dimensional solution is as follows. The first dimension in the sensation-seeking domain is almost synonymous with the Disinhibition scale and is also slightly correlated with the Boredom Susceptibility and Thrill and Adventure-Seeking scales. The second dimension is almost perfectly correlated with the Experience Seeking scale and is also quite highly correlated with the Boredom Susceptibility scale. The third dimension is quite highly correlated with Thrill and Adventure Seeking.

The first rotated dimension in the drug use domain has large loadings for patterns of drug use, which are perhaps indicative of early stages of experimentation with substances (see Huba, Wingard, \& Bentler, 1981). The frequency of using beer, wine, liquor, marijuana, and hashish is correlated highly with the dimension. The second dimension is correlated highly with a variety of drugs, many which might be classified as "hard" substances. Variables that correlate at least moderately with this dimension include marijuana, hashish, coffee, barbiturates, sedatives, amphetamines, other stimulants, LSD and other psychedelics, amyl nitrite, cocaine, and PCP. Finally, the third dimension has high correlations with the usage frequency of such substances as cigarettes and marijuana as well as barbiturates, sedatives, amphetamines, inhalants, nonprescription cough medicines, and PCP.

The pattern of adjusted canonical correlations shown in Table 1 indicates that the first sensation-seeking dimension (Disinhibition) is correlated .41 with the first drug use dimension (alcohol and marijuana use), .15 with the second 
Table 1

Rotated Loadings and Adjusted Canonical Correlations

for One through Three Dimensional Solutions of Sensation Seeking Scales versus Drug Use

\begin{tabular}{|c|c|c|c|c|c|c|}
\hline Variables & I & $I^{\prime}$ & $\mathrm{II}^{\prime}$ & $I^{\prime \prime}$ & II" & III'" \\
\hline \multicolumn{7}{|c|}{ (a) Sensation Seeking Scale Loadings } \\
\hline Experience & .31 & .09 & .72 & .08 & .93 & .24 \\
\hline Thrill \& Adventure & .55 & .63 & -.15 & .22 & .20 & .95 \\
\hline Disinhibition & .99 & .94 & .29 & .96 & .10 & .24 \\
\hline \multicolumn{7}{|l|}{ (b) Drug Use Loadings } \\
\hline Cigarettes & .29 & .09 & .45 & .06 & .11 & .67 \\
\hline Beer & .84 & .82 & .25 & .81 & .18 & .21 \\
\hline Wine & .67 & .60 & .30 & .59 & .27 & .16 \\
\hline Liquor & .81 & .75 & .31 & .75 & .25 & .22 \\
\hline Marijuana & .74 & .52 & .59 & .50 & .36 & .55 \\
\hline Hashish & .58 & .45 & .40 & .44 & .37 & .17 \\
\hline Coffee or tea & .16 & -.04 & .42 & -.04 & .52 & -.02 \\
\hline Minor tranquilizers & .31 & .24 & .22 & .23 & .14 & .19 \\
\hline Major tranquilizers & .29 & .19 & .26 & .18 & .16 & .24 \\
\hline Barbiturates & .41 & .22 & .46 & .21 & .35 & .30 \\
\hline Sedatives & .41 & .17 & .56 & .16 & .44 & .36 \\
\hline Antidepressants & .24 & .13 & .26 & .13 & .20 & .17 \\
\hline Amphetamines & .48 & .31 & .45 & .30 & .34 & .31 \\
\hline Other stimulants & .26 & .07 & .42 & .07 & .43 & .10 \\
\hline LSD & .49 & .25 & .57 & .24 & .58 & .17 \\
\hline Other psychedelics & .31 & .10 & .47 & .10 & .42 & .22 \\
\hline Inhalants & .25 & .17 & .20 & .15 & -.03 & .43 \\
\hline Amyl nitrite & .28 & .16 & .28 & .17 & .32 & .02 \\
\hline Non-Rx sleeping pills & .28 & .19 & .24 & .18 & .14 & .24 \\
\hline Non-Rx stimulants & .23 & .13 & .26 & .12 & .25 & .09 \\
\hline Non-Rx cough medicine & .15 & -.00 & .31 & -.01 & .18 & .31 \\
\hline Non-Rx cold medicine & .19 & .08 & .27 & .07 & .21 & .17 \\
\hline Cocaine & .44 & .24 & .48 & .24 & .49 & 14 \\
\hline Heroin & .07 & .16 & -.16 & .16 & -.25 & .10 \\
\hline Other narcotics & .34 & .22 & .32 & .21 & .26 & .19 \\
\hline Phencyclidine (PCP) & .42 & .21 & .51 & .19 & .40 & .34 \\
\hline \multicolumn{7}{|c|}{ (c) Adjusted canonical correlations } \\
\hline $\bar{I}$ & .52 & .47 & .15 & .41 & .15 & .21 \\
\hline II & & .02 & .30 & -.03 & .27 & .03 \\
\hline III & & & & .23 & .05 & -.17 \\
\hline
\end{tabular}


use dimension (polydrug use), and .21 with the third drug use dimension (cigarettes and hard drugs). The second sensation-seeking dimension (Experience Seeking) is correlated at a nontrivial level (.27) only with the second dimension in the drug use domain. Finally, the third dimension of sensation seeking (Thrill and Adventure Seeking) is positively correlated (.23) with the use of alcohol and marijuana and negatively correlated $(-.17)$ with a dimension indicative of the use of cigarettes and hard drugs. It should be emphasized that it is the nonzero, off-diagonal canonical correlation that might be argued to provide theoretically important "dynamic" information about how types of sensation seeking are related to more than one type of drug use.

Corresponding to the different canonical solutions is a maximum likelihood interbattery factor analysis solution which, before rotation, is related to the canonical solution by a simple column rescaling. Browne (1979) has stated that Rao (1973) showed the correspondence between the Bartlett (or Lawley approximation) stepdown test for the number of canonical correlations exceeding zero and a test for the number of interbattery factors. Consequently, it may also be concluded that three maximum likelihood interbattery factors are necessary. One, as well as two and three, rotated interbattery factor solutions are shown in Table 2.

To maintain comparability with the previously discussed canonical solution, attention will be focused on the three-factor solution loadings. The first factor has loadings for Disinhibition and Thrill and Adventure Seeking in the sensation-seeking domains as well as the usage frequency of beer, wine, liquor, marijuana, and hashish. The second factor has loadings for Experience Seeking and Boredom Susceptibility in the sensation-seeking domain as well as loadings for the usage frequency of marijuana, coffee, LSD, and cocaine. The third factor has a negative loading for Thrill and Adventure Seeking as well as positive loadings for cigarettes and marijuana and a much smaller loading for inhalants.

In general, it would seem that many of the same interpretations can be drawn from either the canonical correlation or interbattery factor analysis results. First, the large loadings in corresponding places are generally about the same. The interbattery loadings are "smaller," but this is due primarily to the rescaling by the square root of the canonical correlations and not an interaction of the rescaling and transformation method. In general, the columns in the rotated interbattery and canonical solutions are proportional, with relatively large loadings remaining large. A seeming point of discrepancy between the two analyses is that the first interbattery factor has loadings for both Thrill and Adventure Sceking and Disinhibition, while these scales are split over two dimensions in the canonical results. The difference can be reconciled by noting that the interpretation of the first and third variates in the canonical solution, coupled with the asymmetric nature of the adjusted canonical correlations, is pointing toward the same relationship.

Information about the degree of association between the drug use and sensation-seeking domains is given in different places in the two types of analyses. In the canonical solution, the rather small size of the canonical correlations points to the fact that the two domains, while significantly related, overlap to only a modest degree. In the interbattery analysis, the rather modest loadings and small communalities for the variable in the two domains point out the same phenomenon.

From both types of solution, then, it may be inferred that Disinhibition tendencies are related to a pattern of alcohol and marijuana use: The canonical correlation results merely show that the two sorts of tendencies are related, while the interbattery model further postulates that Disinhibition sensation-seeking tendencies and frequencies of alcohol and marijuana use share a common cause. Choosing between the two models, of course, must be done on grounds that transcend mere obtained empirical relationships. It is reassuring, however, to find that the different models will allow for approximately the same statement of the degree and type of relationship. Similarly, both the interbattery and canonical correlation models permit the argument 
Table 2

Rotated Loadings for One through Three

Interbattery Factor Solutions

of Sensation Seeking Scales and Drug Use

\begin{tabular}{|c|c|c|c|c|c|c|}
\hline Variables & I & $I^{\prime}$ & $\mathrm{II}^{\prime}$ & $I^{\prime \prime}$ & II" & III" \\
\hline Experience & .22 & .01 & .41 & .00 & .51 & -.04 \\
\hline Thrill \& Adventure & .40 & .43 & .05 & .40 & .24 & -.31 \\
\hline Disinhibition & .71 & .61 & .36 & .62 & .29 & .19 \\
\hline Boredom Susceptibility & .28 & .11 & .37 & .12 & .31 & .19 \\
\hline Cigarettes & .21 & .08 & .27 & .11 & .10 & .34 \\
\hline Beer & .60 & .56 & .23 & .57 & .20 & .10 \\
\hline Wine & .48 & .42 & .24 & .42 & .22 & .08 \\
\hline Liquor & .58 & .52 & .26 & .53 & .23 & .11 \\
\hline Marijuana & .53 & .38 & .40 & .40 & .28 & .28 \\
\hline Hashish & .42 & .32 & .28 & .32 & .26 & .10 \\
\hline Coffee or tea & .12 & -.01 & .24 & .01 & .28 & .01 \\
\hline Minor tranquilizers & .22 & .17 & .15 & .18 & .11 & .10 \\
\hline Major tranquilizers & .21 & .14 & .17 & .15 & .12 & .12 \\
\hline Barbiturates & .29 & .17 & .29 & .18 & .23 & .16 \\
\hline Sedatives & .29 & .14 & .34 & .15 & .27 & .19 \\
\hline Antidepressants & .17 & .10 & .16 & .11 & .13 & .09 \\
\hline Amphetamines & .35 & .23 & .29 & .24 & .23 & .17 \\
\hline Other stimulants & .19 & .07 & .24 & .07 & .25 & .07 \\
\hline LSD & .35 & .19 & .35 & .20 & .35 & .11 \\
\hline Other psychedelics & .22 & .09 & .28 & .10 & .25 & .12 \\
\hline Inhalants & .18 & .13 & .14 & .14 & .02 & .21 \\
\hline Amyl nitrite & .20 & .12 & .18 & .12 & .19 & .02 \\
\hline Non-Rx sleeping pills & .20 & .14 & .16 & .15 & .11 & .12 \\
\hline Non-Rx stimulants & .17 & .10 & .16 & .10 & .16 & .05 \\
\hline Non-Rx cough medicine & .10 & .02 & .18 & .03 & .11 & .16 \\
\hline Non-Rx cold medicine & .14 & .06 & .16 & .07 & .13 & .09 \\
\hline Cocaine & .32 & .19 & .30 & .19 & .30 & .09 \\
\hline Heroin & .05 & .10 & -.07 & .11 & -.11 & .04 \\
\hline Other narcotics & .24 & .16 & .20 & .17 & .17 & .10 \\
\hline Phencyclidine (PCP) & .30 & .16 & .32 & .17 & .25 & .18 \\
\hline
\end{tabular}

that Experience Seeking and Boredom Susceptibility tendencies are related to the use of a variety of "hard drugs," while part of Thrill and Adventure Seeking is modestly related in a negative direction to cigarette and marijuana use.

Since there were relatively low levels of internal consistency for the individual sensationseeking scales, it seemed desirable to rerun the canonical correlation and interbattery analyses using the original items in order to determine whether the general pattern of specific results and the relative findings for the different models change in any major way.

In the canonical correlation analysis of the 16 sensation-seeking items versus the 26 drug use variables, there was a significant relationship 
Table 3

Rotated Loadings and Adjusted Canonical Correlations for One through Three Dimensional Solutions of Sensation Seeking Items versus Drug Use

\begin{tabular}{|c|c|c|c|c|c|c|}
\hline Variables & I & $I^{\prime}$ & II $^{\prime}$ & $I^{\prime \prime}$ & $\mathrm{II}^{\prime \prime}$ & III" \\
\hline \multicolumn{7}{|c|}{ (a) Sensation Seeking Item Loadings } \\
\hline explore strange places & .32 & .31 & .23 & .18 & .48 & .26 \\
\hline mountain climber & .29 & .31 & -.39 & .09 & .08 & .71 \\
\hline like wild parties & .96 & .96 & .06 & .96 & .06 & .16 \\
\hline hate movie 2 nd time & .14 & .15 & -.07 & .09 & .05 & .19 \\
\hline like modern paintings & .09 & .06 & .38 & -.03 & .57 & .06 \\
\hline like frightening things & .47 & .48 & -.17 & .41 & -.02 & .31 \\
\hline like real "swingers" & .70 & .70 & .04 & .62 & .21 & .30 \\
\hline bored seeing same kids & .21 & .18 & .38 & .16 & .43 & -.05 \\
\hline try new foods & .08 & .06 & .24 & -.09 & .55 & .25 \\
\hline try parachute jumping & .27 & .29 & -.24 & .12 & .11 & .51 \\
\hline be in "jet" set & .39 & .39 & .06 & .29 & .27 & .27 \\
\hline bored if people say same thing & .14 & .11 & .51 & .14 & .42 & -.26 \\
\hline dress way want & .16 & .14 & .37 & .16 & .30 & -.18 \\
\hline enjoy skiing steep mountain & .36 & .38 & -.32 & .16 & .13 & .68 \\
\hline like "sexy" movies & .36 & .36 & -.09 & .42 & -.21 & -.03 \\
\hline $\begin{array}{l}\text { restless when home too much } \\
\text { (b) Drug Use Loadings }\end{array}$ & .33 & .32 & .23 & .34 & .19 & -.08 \\
\hline Cigarettes & .34 & .08 & .50 & .06 & .60 & .08 \\
\hline Beer & .85 & .82 & .30 & .81 & .29 & .18 \\
\hline Wine & .66 & .58 & .32 & .57 & .18 & .31 \\
\hline L.iquor & .84 & .77 & .35 & .75 & .27 & .27 \\
\hline Marijuana & .78 & .47 & .70 & .45 & .68 & .32 \\
\hline Hashish & .59 & .45 & .40 & .43 & .19 & .42 \\
\hline Coffee or tea & .14 & -.04 & .33 & -.06 & .07 & .43 \\
\hline Minor tranquilizers & .26 & .22 & .15 & .21 & .01 & .23 \\
\hline Major tranquilizers & .25 & .17 & .18 & .17 & .13 & .13 \\
\hline Barbituarates & .36 & .17 & .41 & .15 & .24 & .35 \\
\hline Sedatives & .41 & .19 & .46 & .16 & .21 & .48 \\
\hline Antidepressants & .19 & .10 & .20 & .09 & .01 & .29 \\
\hline Amphetamines & .45 & .27 & .42 & .25 & .21 & .41 \\
\hline Other stimulants & .22 & .05 & .33 & .04 & .03 & .47 \\
\hline LSD & .45 & .22 & .48 & .20 & .16 & .57 \\
\hline Other psychedelics & .29 & .09 & .40 & .08 & .21 & .37 \\
\hline
\end{tabular}

-continued on the next page- 
Table 3 , continued

\begin{tabular}{lcrrrrr}
\hline Variables & I & $I^{\prime}$ & $I^{\prime}$ & $I^{\prime \prime}$ & $I^{\prime \prime}$ & III" \\
\hline Inhalants & .24 & .10 & .29 & .09 & .41 & -.03 \\
Amyl nitrite & .29 & .18 & .24 & .17 & .10 & .26 \\
Non-Rx sleeping pills & .25 & .11 & .29 & .10 & .20 & .22 \\
Non-Rx stimulants & .27 & .13 & .30 & .11 & .14 & .31 \\
Non-Rx cough medicines & .14 & -.05 & .32 & -.06 & .31 & .13 \\
Non-Rx cold medicines & .17 & .03 & .27 & .02 & .17 & .22 \\
Cocaine & .43 & .23 & .44 & .21 & .10 & .56 \\
Heroin & .02 & .14 & -.17 & .14 & -.02 & -.23 \\
Other Narcotics & .33 & .21 & .29 & .19 & .17 & .26 \\
Phencyclidine (PCP) & .42 & .19 & .47 & .17 & .29 & .40 \\
(c) Adjusted canonical correlations & & & & & \\
I & .60 & .51 & .30 & .46 & .31 & .16 \\
II & & -.13 & .27 & -.05 & .06 & .30 \\
III & & & & .25 & -.18 & .10 \\
\hline
\end{tabular}

between domains: $\chi^{2}(416)=952.84, p<.001$. The size of the 15 canonical correlations (.60, $.30, .28, .21, .21, .20, .19, .17, .16, .13, .12, .11$, $.10, .09, .09, .05)$ suggests that either two or three dimensions are necessary to span the domains. As in the analysis with the SensationSeeking Scale scores, two dimensions were found to be inadequate to fully explain the covariation among domains: $\chi^{2}(336)=393.39$, $p<.02$, but three dimensions were adequate: $\chi^{2}$ (299) $=307.11, p=.36$.

When different measures of multivariate correlation are examined, it is again found that the conclusion is accepted that the domains are only modestly interrelated. The square root of $\gamma_{5}$ is .24 , while the square root of $\gamma_{6}$ is .23 . Examining the redundancy coefficients, $6.93 \%$ of the variance in the drug use items is explained by the sensation-seeking items, whereas $6.34 \%$ of the variance in the sensation-seeking items is explained by the drug use variables.

As in the analysis with the scale scores, although three dimensions are statistically necessary to explain the observed pattern of acrossdomain covariation, it is possible that a lower dimensionality solution will be judged to be more satisfactory. Again, the one-dimensional solution as well as the two- and three-dimensional rotated solutions were examined. The loadings on the orthogonally transformed variates are shown in Table 3, which also shows the adjusted canonical correlations.

From Table 3 it appears that the general interpretations made for the scale scores are replicated at the item level. Indeed, even with the slight change in battery composition, the parameter estimates for the drug use variables are almost identical in numerical value when compared to the results for the scale scores given in Table 1. (Note that the third drug use dimension in Table 1 is the second drug use dimension in Table 3 and vice versa). The results are so conceptually similar that no additional discussion needs to be made.

Corresponding to the canonical correlation solutions of the sensation-seeking items versus the drug use variables, one through three interbattery factor solutions were developed by rescaling the canonical loadings. The interbattery factors were orthogonally rotated using orthosim. The rotated loadings are shown in Table 4. Again, the pattern of loadings is predictable 
Table 4

Rotated Loadings for One through Three

Interbattery Factor Solutions

of Sensation Seeking Items and Drug Use

\begin{tabular}{|c|c|c|c|c|c|c|}
\hline Variables & $\mathrm{I}$ & $I^{\prime}$ & $\mathrm{II}^{\prime}$ & $I^{\prime \prime}$ & II $^{\prime \prime}$ & III $^{\prime \prime}$ \\
\hline explore strange places & .25 & .14 & .23 & .13 & -.03 & .34 \\
\hline mountain climber & .22 & .31 & -.06 & .24 & -.30 & .17 \\
\hline like wild parties & .74 & .62 & .41 & .67 & .20 & .25 \\
\hline hate movie 2nd time & .11 & .12 & .02 & .10 & -.06 & .07 \\
\hline like modern paintings & .07 & -.06 & .21 & -.07 & .02 & .30 \\
\hline like frightening things & .36 & .36 & .11 & .36 & -.03 & .12 \\
\hline like real "swingers" & .54 & .45 & .30 & .47 & .05 & .28 \\
\hline bored seeing same kids & .16 & .02 & .26 & .04 & .11 & .25 \\
\hline try new foods & .06 & -.02 & .14 & -.06 & -.09 & .31 \\
\hline try parachute jumping & .21 & .25 & .00 & .20 & -.20 & .16 \\
\hline be in "jet" set & .30 & .24 & .19 & .23 & -.02 & .24 \\
\hline bored if people say same thing & .11 & -.06 & .29 & -.03 & 20 & .21 \\
\hline dress way want & .12 & -.01 & .23 & .02 & .16 & .17 \\
\hline enjoy skiing steep mountain & .28 & .33 & .00 & .27 & -.26 & .20 \\
\hline like "sexy" movies & .28 & .26 & .10 & .30 & .11 & -.03 \\
\hline restless when home too much & .25 & .15 & .24 & .18 & 15 & .16 \\
\hline Cigarettes & .26 & .10 & .32 & .18 & .32 & .10 \\
\hline Beer & .66 & .60 & .28 & .63 & .08 & .20 \\
\hline Wine & .51 & .44 & .27 & .45 & .04 & .25 \\
\hline Liquor & .66 & .57 & .31 & .60 & .07 & .25 \\
\hline Marijuana & .60 & .39 & .49 & .47 & .33 & .27 \\
\hline Hashish & .45 & .35 & .30 & .36 & .06 & .29 \\
\hline Coffee or tea & .11 & .00 & .20 & .00 & .04 & .24 \\
\hline Minor tranquilizers & .20 & .16 & .12 & .16 & -.02 & .15 \\
\hline Major tranquilizers & .19 & .14 & .13 & .15 & .06 & .10 \\
\hline Barbiturates & .28 & .16 & .27 & .18 & 12 & .24 \\
\hline Sedatives & .31 & .17 & .31 & .19 & 10 & .31 \\
\hline Antidepressants & .15 & .09 & .13 & .08 & .00 & .17 \\
\hline Amphetamines & .35 & .22 & .29 & .24 & .09 & .28 \\
\hline Other Stimulants & .17 & .07 & .21 & .06 & .01 & .28 \\
\hline LSD & .34 & .20 & .32 & .20 & .07 & .36 \\
\hline Other psychedelics & .23 & .10 & .26 & .12 & .11 & .24 \\
\hline Inhalants & .18 & .09 & .19 & .15 & .21 & .02 \\
\hline Amyl nitrite & .22 & .15 & .17 & .16 & .04 & .18 \\
\hline
\end{tabular}

-continued on the next page- 
Table 4 , continued

\begin{tabular}{llllllr}
\hline Variables & I & I' $^{\prime}$ & II' $^{\prime}$ & I" $^{\prime \prime}$ & II $^{\prime \prime}$ & III" $^{\prime \prime}$ \\
\hline Non-Rx sleeping pills & .19 & .10 & .19 & .12 & .10 & .15 \\
Non-Rx stimulants & .21 & .11 & .20 & .12 & .06 & .20 \\
Non-Rx cough medicine & .10 & .00 & .19 & .03 & .18 & .09 \\
Non-Rx cold medicine & .13 & .05 & .17 & .06 & .09 & .14 \\
Cocaine & .33 & .20 & .30 & .20 & .04 & .35 \\
Heroin & .02 & .08 & -.09 & .08 & -.03 & -.12 \\
Other narcotics & .25 & .17 & .20 & .18 & .07 & .18 \\
Phencyclidine (PCP) & .32 & .18 & .31 & .20 & .14 & .27 \\
\hline
\end{tabular}

from the analysis of scale scores previously considered. Similarly, the interbattery solution appears to support the same conclusions as the canonical correlation solution.

\section{Discussion}

It is apparent that despite a few minor discrepancies, and bearing in mind the scaling differences between the canonical correlation and interbattery factor analysis methods, the alternate solutions presented very similar results. In all cases, sensation seeking and drug use were moderately associated in the sample of adolescents.

When comparing the canonical correlation and interbattery factor analysis solutions that used the Sensation-Seeking Scales with the analogous two solutions using the sensation-seeking items, scale integrity was not always retained. For example, the entire Experience Seeking scale was preserved in Dimension II (always considering the three-factor solutions) of the canonical correlation analysis (Table 3 ), while three of the four items were retained in Dimension III of the interbattery factor analysis solution (Table 4). In general, the canonical correlation analyses preserved the scale integrity more effectively than did the interbattery solution. However, this would be expected in light of the conceptual and methodological differences in the two methods.
Using the full Sensation-Seeking Scale (Form V-10 items per scale), Ridgeway and Russell (1980) found a pattern of internal consistency coefficients similar to that of the authors for these scales in their sample of college students. They obtained alpha coefficients ranging from .48 to .69 that are identical in terms of rank order of magnitude with those obtained in this study. The results of this study and those of Ridgeway and Russell (1980) clearly question the high scale reliabilities reported by Zuckerman et al. (1978). On the other hand, an average coefficient alpha of .56 was obtained in this study, whereas Ridgeway and Russell (1980) obtained only a slightly higher average of .59 on all four scales using 10 items per scale. This seems to indicate that the four-item scales have greater economy and parsimony than the 10 -item scales, while sacrificing a negligible amount of internal consistency. In general, the different sensationseeking constructs are somewhat abstract, and the indicators are only moderately correlated with one another.

There are two conceptual perspectives on how sensation seeking and drug use interrelate. One perspective, advocated by Zuckerman (e.g., Zuckerman et al., 1980), is that each person has an individual optimal level of physiological arousal and that drug use and sensation-seeking tendencies are motivated by this physiological need. For example, a person who has a high innate 
physiological need for stimulation will seek out those experiences that will increase their arousal level, such as exciting and stimulating activities (and thus would score high on sensation-seeking scales) and mood-altering drugs (and would likewise report high drug use). This perspective reflects a self-medicative or compensatory use of drugs and exciting activities to achieve an optimal level of physiological arousal. The second perspective (see Segal et al., 1980) emphasizes the psychological need (personality trait) for stimulation, sensory variety and novelty, and theorizes that drug use is caused by this personality need for novel stimulation. This perspective emphasizes the role of drug use to augment emotional state rather than to compensate for a physiological arousal imbalance. The two statistical methods contrasted in the analyses in this paper parallel these two perspectives, such that the canonical correlation approach stresses the latter argument, implying that drug use is caused by sensation seeking, while the interbattery factor analysis approach assumes that some underlying factor (presumably a physiological need for arousal and stimulation in this case) causes both drug use and sensation-seeking activities. Since the results from both methods are quite similar, it is not possible to say which of the two perspectives the data favor.

Although the analyses leave little doubt that there is a moderate relationship between sensation seeking and drug use, similar to previous research on noninstitutionalized populations (e.g., Zuckerman, 1979), the association is not a general one as would perhaps appear to be true for indices equivalent to the number of drugs used by college students (Segal et al., 1980) or addicts (Kaestner, Rosen, \& Apel, 1977; Kohn, Barnes, Fishlinsky, Segal, \& Hoffman, 1979). In order to gain a substantive understanding of the results, it is necessary to examine several patterns that emerged from the analyses.

Disinhibition, which is characterized by a desire for active social affiliation and participation, is related to a pattern of alcohol and cannabis use. A similar finding regarding alcohol was reported by Schwartz, Burkhart, and Green
(1978) for a sample of college students. Alcohol and cannabis are well noted for facilitating social interaction, at least in small to moderate quantities.

Thrill and Adventure Seeking is related to two patterns of drug use. Similar to Disinhibition, it is positively related to alcohol and cannabis use but negatively related to the (more commited?) use of cigarettes, sedatives, amphetamines, inhalants, PCP, and marijuana. The content of the Thrill and Adventure Seeking scale is related to risky and frightening physical endeavors. Individuals drawn to these types of activities may have a strong awareness of and concern for their physical well being and thus may avoid the regular use of those drugs that are likely to damage their bodies or to diminish physical responsivity and agility. Concomitantly, for adolescents, marijuana and alcohol may be used either to make mundane activities more exciting or because it is thrilling to engage in illegal activities with modest but not overwhelming penalties.

Experience Seeking and Boredom Susceptibility are related to the use of stimulants (caffeine, marijuana, amphetamines, cocaine), depressants (sedatives, barbiturates), and major moodaltering drugs (LSD, other psychedelics, PCP). Both of these sensation-seeking scales are concerned with novelty, uniqueness, curiosity, and nonrepetitiveness. These drug effects apparently facilitate Experience Seeking and combat Boredom Susceptibility.

The results in this paper support the connection between various types of sensation-seeking behaviors and several drug use patterns. The connection seems specific rather than global. Whether the results reflect underlying factors influencing both domains or whether one domain has a causal relationship with the other remains equivocal. Interpretations of the data supporting either argument could be made. The contrast of the two methodological approaches (canonical correlation and interbattery factor analysis) clearly substantiates the effectiveness and utility of either. The appropriate choice of one model needs to be based on conceptual and theoretical concerns, since statistical adequacy 
has been demonstrated for both, at least in this example. Longitudinal data and analyses might help partition the covariation into common sources and "reciprocal" effects.

\section{References}

Bentler, P. M. Factor simplicity index and transformations. Psychometrika, 1977, 42, 277-295.

Bentler, P. M., \& Huba, G. J. Symmetric and asymmetric rotations in canonical correlation analy. sis: New methods with drug variable examples. In N. Hirschberg (Ed.), Multivariate methods in the social sciences: Applications. Hillsdale NJ: Erlbaum, in press.

Browne, M. W. The maximum-likelihood solution in interbattery factor analysis. British Journal of Mathematical and Statistical Psychology, 1979, 32, 75-86.

Cliff, N., \& Krus, D. J. Interpretation of canonical analysis: Rotated vs. unrotated solutions. Psychometrika, 1976, 41, 35-42.

Cramer, E. M., \& Nicewander, W. A. Some symmetric, invariant measures of multivariate association. Psychometrika, 1979, 44, 43-54.

Huba, G. J., \& Bentler, P. M. A developmental theory of drug use: Derivation and assessment of a causal modeling approach. In P. B. Baltes \& O. G. Brim, Jr. (Eds.), Life-span development and behavior (Vol. 4). New York: Academic Press, in press.

Huba, G. J., Palisoc, A. L., \& Bentler, P. M. ORSIM2: A FORTRAN program for symmetric and asymmetric orthogonal rotation of canonical variates and interbattery factors. American Statistician, in press.

Huba, G. J., Wingard, J. A., \& Bentler, P. M. Beginning adolescent drug use and peer and adult interaction patterns. Journal of Consulting and Clinical Psychology, 1979, 47, 265-276.

Huba, G. J., Wingard, J. A., \& Bentler, P. M. Longitudinal analysis of the role of peer support, adult models, and peer subcultures in beginning adolescent substance use: An application of setwise canonical correlation methods. Multivariate $\mathrm{Be}$ havioral Research, 1980, 15, 259-280.

Huba, G. J., Wingard, J. A., \& Bentler, P. M. A comparison of two latent variable causal models for adolescent drug use. Journal of Personality and Social Psychology, 1981, 40, 180-193.

Kaestner, E., Rosen, L., \& Appel, P. Patterns of drug abuse: Relationships with ethnicity, sensation seeking, and anxiety. Journal of Consulting and Clinical Psychology, 1977, 45, 462-468.
Khavari, K. A. Mabry, E., \& Humes, M. Personality correlates of hallucinogen use. Journal of $A b$ normal Psychology, 1977, 86, 172-178.

Kohn, P. M., Barnes, G. E., Fishlinsky, M., Segal, R., \& Hoffman, F. M. Experience-seeking characteristics of methadone clients. Journal of Consulting and Clinical Psychology, 1979, 47. 980-981.

Mardia, K. V., Kent, J. T., \& Bibby, J. M. Multivariate analysis. New York: Academic Press, 1979.

Rao, C. R. Linear statistical interference and its applications. New York: Wiley, 1973.

Ridgeway, D., \& Russell, J. A. Reliability and validity of the Sensation-Seeking Scale: Psychometric problems in Form V. Journal of Consulting and Clinical Psychology, 1980, 48, 662-664.

Schwartz, R. M., Burkhart, B. R., \& Green, B. Turning on or turning off: Sensation seeking or tension reduction as motivational determinants of alcohol use. Journal of Consulting and Clinical Psychology, 1978, 46. 1144-1145.

Segal, B., Huba, G. J., \& Singer, J. L. Drugs, daydreaming, and personality: $A$ study of college youth. Hillsdale NJ: Erlbaum, 1980.

Skinner, H. A. Exploring relationships among multiple data sets. Multivariate Behavioral Research, 1977, 12, 199-220.

Skinner, H. A. The art of exploring predictor-criterion relationships. Psychological Bulletin, 1978, 85 . 327-337.

Stewart, D., \& Love, D. A general canonical correlation index. Psychological Bulletin, 1968, 70. 160-163.

Timm, N. H. Multivariate analysis with applications in education and psychology. Monterey CA: Brooks-Cole, 1975.

Tucker, L. R. An inter-battery method of factor analysis. Psychometrika, 1958, 23, 111-136.

Wingard, J. A., Huba, G. J., \& Bentler, P. M. A longitudinal analysis of personality structure and adolescent substance use. Personality and Individual Differences, 1980, 1, 259-272.

Zuckerman, M. Sensation seeking. In H. London \& J. Exner (Eds.), Dimensions of personality. New York: Wiley, 1978.

Zuckerman, M. Sensation seeking: Beyond the optimal level of stimulation. Hillsdale NJ: Erlbaum, 1979.

Zuckerman, M., Buchsbaum, M. S., \& Murphy, D. L. Sensation seeking and it biological correlates. Psychological Bulletin, 1980, 88, 187-214.

Zuckerman, M., Eysenck, S., \& Eysenck, H. J. Sensation seeking in England and America: Cross-cultural, age, and sex comparisons. Journal of Consulting and Clinical Psychology, 1978, 46, 139-149. 


\section{Ackmowledgments}

This research was partially supported by Grant Number DA01070 from the National Institute on Drug Abuse. The authors thank Julie Honig and Suong Luong for production assistance and Arthur L. Palisoc for programming aid.

\section{Author's Address}

Send requests for reprints or further information to G. J. Huba, Department of Psychology, University of California, 405 Hilgard Avenue, Los Angeles CA 90024. 